УДК 661.8:542:543.552:546.59

\title{
ВОЛЬТАМПЕРОМЕТРИЧЕСКОЕ ОПРЕДЕЛЕНИЕ ТИОСУЛЬФАТ-ИОНОВ НА МОДИФИЦИРОВАННОМ ЧАСТИЦАМИ ЗОЛОТА УГЛЕРОДСОДЕРЖАЩЕМ КОМПОЗИТНОМ ЭЛЕКТРОДЕ
}

\author{
Аксиненко Ольга Сергеевна 1 , \\ crumba88@mail.ru
}

\author{
Коршунов Андрей Владимирович2, \\ korshunovav@mgsu.ru
}

\author{
Ковалева Светлана Владимировна 3 , \\ svetkovaleva@rambler.ru \\ 1 Управление образования Администрации Томского района, \\ Россия, 634009 г. Томск, пер. Кооперативный, 2а. \\ 2 Московский государственный строительный университет, \\ Россия, 129337 г. Москва, Ярославское шоссе, 26. \\ 3 Томский государственный педагогический университет, \\ Россия, 634061 г. Томск, ул. Киевская, 60.
}

\begin{abstract}
Актуальность. Тиосульфраты находят широкое применение в промышленности (текстильное производство, водоочистка, извлечение металлов), сельском хозяйстве (контроль иветения растений, фумигация почв, удобрения), медицине (детоксикационная терапия), аналитической химии. Области практического использования тиосульфатов определяются их высокой восстановительной и комплексообразующей активностью, а также продуктами окисления, имеющими самостоятельное практическое значение (коллоидная сера, политионаты). Несмотря на длительный опыт применения тиосульфатов, до сих пор продолжается поиск экспрессных, чувствительных и доступных методов их определения в технологических средах, объектах окружающей среды, продуктах питания. В связи с этим совершенствование методов определения тиосульфатов является актуальной задачей.

Цель: определить условия получения аналитического сигнала при электроокислении тиосульфрат-ионов с использованием модифицированного частицами золота углеродсодержащего композитного электрода.

Объекты: растворы тиосульфата натрия.

Методы: вольтамперометрия постоянного тока с линейной разверткой потенциалов, циклическая вольтамперометрия, растровая электронная микроскопия, рентгеноспектральный микроанализ, моделирование окислительно-восстановительных равновесий.

Результаты. Электроокисление тиосульфат-ионов на модифицированном частицами золота углеродсодержащем композитном электроде в условиях постояннотоковой вольтамперометрии с линейной разверткой потенциалов в фоновых электролитах 0,05 $\mathrm{M} \mathrm{KNO}_{3}$ или 0,05 $\mathrm{M} \mathrm{Na}_{2} \mathrm{SO}_{4}$ протекает при потенциалах 0,2..0,6 B и 0,8...1,3 В (х. с. э.) с максимумами анодного тока при $E_{p, 1} \approx 0,3$ B и $E_{p, 2 \approx 1,1}$ B. Величина анодного тока $I_{p, 2}$ на порядок выше величины $l_{p, 1}$, концентрационные зависимости $l_{p, 1}$ и $I_{p, 2}$ являются линейными в интервалах $c\left(S_{2} \mathrm{O}_{3}{ }^{2-}\right)=1 \cdot 10^{-6} \ldots 1 \cdot 10^{-5} \mathrm{M}$ и $1 \cdot 10^{-7} \ldots 1 \cdot 10^{-5} \mathrm{M}$, соответственно. Интерпретация электродных процессов проведена на основе расчётных диаграмм метастабильных ионно-молекулярных форм в системе $\mathrm{S}-\mathrm{Au}-\mathrm{H}_{2} \mathrm{O}$, а также литературных данных. Показано, что максимум анодного тока в области $E_{p, 1}$ обусловлен протеканием совокупности электродных и химических реакций с участием промежуточных продуктов окисления тиосульфата (сульфит-, политионат-ионов, серы, комплексов Аu). Основным процессом в области $E_{p, 2}$ является анодное окисление серы с наложением электрокаталитического цикла с участием (гидр)оксидов Аи. Показана целесообразность использования величины $I_{p, 2}$ при $E_{p, 2 \approx 1,1}$ В для определения низких концентраций $S_{2} \mathrm{O}_{3}{ }^{2-}-$-ионов. Проведена оценка правильности результатов измерений и стабильности электродной ффункции при многократной регистрации аналитического сигнала. Предел обнаружения $\mathrm{S}_{2} \mathrm{O}_{3}{ }^{2-}-$-ионов по предлагаемому методу составляет $\mathrm{C}_{\text {min }}=5 \cdot 10^{-8} \mathrm{M}(7,9$ мка/л), нижняя граница определяемых концентраций $c_{\text {lim }}=1,2 \cdot 10^{-7} \mathrm{M}$. Полученные в работе результаты могут быть использованы при разработке (усовершенствовании) методик определения низких концентраций $\mathrm{S}_{2} \mathrm{O}_{3}{ }^{2-}$-ионов в технологических растворах, объектах окружающей среды, продуктах питания.
\end{abstract}

\section{Ключевые слова:}

Тиосульфат-ионы, частицы золота, углеродсодержащий композитный электрод, нейтральные электролиты, постояннотоковая вольтамперометрия, анодное окисление, метастабильные ионно-молекулярные формы серы.

\section{Введение}

Тиосульфаты находят широкое применение в промышленности, сельском хозяйстве, медицине. Направления их практического использования определяются, прежде всего, высокой восстановительной и комплексообразующей способностью, а также продуктами окисления, имеющими самостоятельное практическое значение (коллоидная сера, политионаты). Высокая восстановительная активность тиосульфатов используется в текстильной промышленности (удаление избытка отбеливателя) [1], кожевенном деле (выделка шкур) [2], системе водоочистки (дехлорирование балластных вод) [3], аналитической химии [4]. В качестве комплексообразующего реагента тио- 
сульфаты натрия и аммония рассматриваются как возможная замена высокотоксичных цианидов при извлечении благородных металлов (золото, серебро) из руд [5]:

$$
\begin{gathered}
4 \mathrm{Au}+\mathrm{O}_{2}+8 \mathrm{~S}_{2} \mathrm{O}_{3}{ }^{2-}+4 \mathrm{H}^{+} \rightarrow 4\left[\mathrm{Au}\left(\mathrm{S}_{2} \mathrm{O}_{3}\right)_{2}\right]^{3-}+2 \mathrm{H}_{2} \mathrm{O} \\
\mathrm{Au}+5 \mathrm{~S}_{2} \mathrm{O}_{3}{ }^{2-}+\left[\mathrm{Cu}\left(\mathrm{NH}_{3}\right)_{4}\right]^{2+} \rightarrow \\
\rightarrow\left[\mathrm{Au}\left(\mathrm{S}_{2} \mathrm{O}_{3}\right)_{2}\right]^{3-}+\left[\mathrm{Cu}\left(\mathrm{S}_{2} \mathrm{O}_{3}\right)_{3}\right]^{5-}+4 \mathrm{NH}_{3} .
\end{gathered}
$$

В медицине восстановительные и комплексообразующие свойства тиосульфата натрия давно используются при лечении отравлений галогенами, цианидами, солями тяжелых металлов, для снижения интоксикации при химиотерапии, при лечении кальциноза, терапии сепсиса [6, 7]:

$$
\begin{gathered}
\mathrm{Na}_{2} \mathrm{~S}_{2} \mathrm{O}_{3}+4 \mathrm{Cl}_{2}+\mathrm{H}_{2} \mathrm{O} \rightarrow 2 \mathrm{NaCl}+2 \mathrm{H}_{2} \mathrm{SO}_{4}+6 \mathrm{HCl} ; \\
\mathrm{Na}_{2} \mathrm{~S}_{2} \mathrm{O}_{3}+\mathrm{KCN} \rightarrow \mathrm{KSCN}+\mathrm{Na}_{2} \mathrm{SO}_{3} ; \\
\mathrm{Ag}^{+}+2 \mathrm{~S}_{2} \mathrm{O}_{3}{ }^{2-} \rightarrow\left[\mathrm{Ag}\left(\mathrm{S}_{2} \mathrm{O}_{3}\right)_{2}\right]^{3-} .
\end{gathered}
$$

В сельском хозяйстве тиосульфаты аммония, натрия, кальция, серебра и других металлов используются в качестве экологически малоопасных реагентов для контроля цветения плодовых, ягодных и декоративных культур, при фумигации почв, в составе удобрений $[8,9]$. При производстве пищевых продуктов $\mathrm{Na}_{2} \mathrm{~S}_{2} \mathrm{O}_{3}$ (добавка Е539) используется в качестве антиоксиданта и комплексообразователя [10]. Таким образом, в связи с обширным перечнем областей применения тиосульфатов совершенствование методов контроля их содержания в технологических средах, объектах окружающей среды, лекарственных препаратах и продуктах питания является актуальной задачей.

Одними из наиболее доступных, чувствительных и экспрессных методов определения соединений серы, в том числе и $\mathrm{S}_{2} \mathrm{O}_{3}{ }^{2-}$-ионов, являются электрохимические методы. Известны варианты как классических (вольтамперометрия, амперометрическое титрование с использованием жидких и твердых индикаторных электродов), так и современных электроаналитических методов определения тиосульфатов, основанных на электрокатализе. Использование классической и переменнотоковой полярографии позволяет определять тиосульфат-ионы в смесях с сульфидами и элементной серой $[11,12]$. Определение проводят в нейтральном или слабощелочном фоновом электролите, токи катодного восстановления тиосульфата на $\mathrm{Hg}$-электроде наблюдаются при $-0,28$ В в переменнотоковом и при $-0,15$ В в постояннотоковом режимах. Сера восстанавливается при более отрицательных потенциалах $-0,6 \ldots-0,9$ В, сульфиды можно удалять в виде сероводорода в среде разбавленной уксусной кислоты путём пропускания азота [11]. Интервал определяемых концентраций $\mathrm{S}_{2} \mathrm{O}_{3}{ }^{2-}$-ионов составляет $10^{-6} \ldots 10^{-4} \mathrm{M}$ [12]. Более высокая чувствительность метода достигается при применении предварительного адсорбционного накопления тиосульфатных $\mathrm{Hg}$ комплексов на ртутной микрокапле при $0,15 \ldots 0,27 \mathrm{~B}$ и их последующем восстановлении при $-0,4 \ldots-0,5 \mathrm{~B}$; предел обнаружения в таком варианте метода может быть снижен до $1,2 \cdot 10^{-8} \mathrm{M}[13]$.
В качестве металлической основы в составе модифицированных электродов могут быть использованы алюминий или цинк [14-16]. Химическое модифицирование поверхности металлической подложки частицами золота [14] или цианидсодержащими комплексами металлов $[14,15]$ позволяет определять тиосульфат-ионы в нейтральных фоновых электролитах по токам электрокаталитического окисления в области потенциалов $0,6 \ldots 0,8$ В (н. к. э.) [16]. Нижний предел определяемых концентраций $\mathrm{S}_{2} \mathrm{O}_{3}{ }^{2-}$-ионов в условиях вольтамперометрии находится на уровне ммоль/л.

В качестве электрокаталитически активных добавок в составе модифицированных электродов на основе углеродсодержащих материалов используются гексацианоферраты кобальта и никеля, оксиды никеля, производные ферроцена, бипиридиновые комплексы рутения [17-21]. Сущность процессов с участием таких добавок заключается в генерации медиаторов $\left(\mathrm{Co}^{+3}, \mathrm{Fe}^{+3}, \mathrm{Ni}^{+3}, \mathrm{Ru}^{+3}\right.$ и др.) в условиях анодной поляризации электрода, которые далее окисляют $\mathrm{S}_{2} \mathrm{O}_{3}{ }^{2-}$-ионы. Процесс проводят, как правило, в нейтральном или слабощелочном фоновом электролите (нитраты или хлориды Na или К, фосфатный буфер), окисление тиосульфата протекает в области потенциалов $0,5 \ldots 0,8$ В (х. с. э.), интервал линейности концентрационной зависимости аналитического сигнала в среднем составляет $10^{-6} \ldots 10^{-4} \mathrm{M}$. Наиболее низкие определяемые концентрации $\mathrm{S}_{2} \mathrm{O}_{3}{ }^{2-}$-ионов достигаются при использовании электродов, модифицированных производными ферроцена, комплексами рутения, медью (предел обнаружения порядка $10^{-7} \mathrm{M}$ ) [20-22]. Перспективным является использование стеклоуглеродного электрода, модифицированного углеродными нанотрубками [23], а также алмазного электрода, допированного бором, в режиме амперометрического детектирования [24].

Необходимо отметить, что рассмотренные выше химически модифицированные электроды, несмотря на хорошие аналитические характеристики, обладают рядом существенных недостатков при систематическом применении на практике: процедура модифицирования является многостадийной и длительной; такие электроды требуют соблюдения специальных условий использования и хранения; поверхность электрода быстро блокируется загрязнениями, в том числе серой и её соединениями. Вместе с тем возможности использования доступных и относительно простых в приготовлении углеродсодержащих электродов, модифицированных частицами благородных металлов, изучены недостаточно. В связи с этим целью настоящей работы являлось определение условий получения аналитического сигнала при электроокислении тиосульфат-ионов с использованием модифицированного частицами золота углеродсодержащего композитного электрода.

\section{Материалы и методы исследования}

В работе использованы реактивы квалификации «х. ч.» и «ч. Д. а.» без дополнительной очистки: тиосульфат натрия $\mathrm{Na}_{2} \mathrm{~S}_{2} \mathrm{O}_{3} \cdot 5 \mathrm{H}_{2} \mathrm{O}$, сульфат натрия $\mathrm{Na}_{2} \mathrm{SO}_{4}$, 
нитрат калия $\mathrm{KNO}_{3}$. Исходные растворы веществ с концентрацией 0,1 М готовили растворением точных навесок реагентов в рассчитанном объеме бидистиллированной воды. Рабочие растворы с меньшей концентрацией реагентов готовили путем разбавления исходных растворов. Рабочий раствор $1 \cdot 10^{-4} \mathrm{M}$ $\mathrm{Na}_{2} \mathrm{~S}_{2} \mathrm{O}_{3}$ готовили непосредственно перед проведением экспериментов путём разбавления исходного 0,1 М раствора в предварительно прокипяченной и охлажденной бидистиллированной воде. Для проведения электрохимических измерений использовали трёхэлектродную кварцевую ячейку вместимостью 20 мл с неразделенным межэлектродным пространством. В качестве рабочего электрода использовали композитный электрод (НПП «Томьаналит»), состоящий из полиэтиленового корпуса, заполненного смесью полиэтилена (70 мас. \%) с добавкой высокодисперсного углерода (30 мас. \%) при помощи литья под давлением. Обновление рабочей поверхности электрода осуществляли срезанием тонкого слоя (0,1 ..0,3 мм). Модифицирование поверхности композитного электрода частицами золота проводили методом электроосаждения из раствора, содержащего $500 \mathrm{мг} / л \mathrm{HAuCl}_{4}$ (готовили из стандартного образца ГСО 8429-2003), при потенциале $-0,1$ В (х. с. э.) в течение 60 с. Электродом сравнения и вспомогательным электродом служили хлорсеребряные электроды (Ag/ $\mathrm{AgCl} / 1 \mathrm{M}$ $\mathrm{KCl})$. Для проведения вольтамперометрических измерений в постояннотоковом режиме с линейной разверткой потенциала использовали анализатор TA-Lab (НПП «Томьаналит»). Перед регистрацией вольтамперограмм из исследуемых растворов удаляли растворенный кислород путем барботирования азота высокой чистоты. Морфологию и состав поверхностного слоя модифицированного электрода контролировали при помощи растрового электронного микроскопа Philips SEM 515 с приставкой EDAX ECON IV.

\section{Результаты и их обсуждение}

Микрофотография поверхности углеродсодержащего композитного электрода, модифицированного частицами золота (АиУКЭ), приведена на рис. 1. Распределение частиц $\mathrm{Au}$ по поверхности композитной матрицы является относительно равномерным, размеры единичных частиц металла составляют в среднем $100 \ldots 200$ нм. Частицы образуют неплотные агрегаты, размеры которых в зависимости от условий осаждения составляют $0,5 \ldots 0,8$ мкм. По данным рентгеноспектрального микроанализа в состав поверхности модифицированного электрода входят два элемента - углерод и золото (рис. 1), присутствие других элементов в пределах чувствительности метода не обнаружено.

В качестве фоновых электролитов в работе были использованы средние соли с одно- и двухзарядными анионами - нитрат калия и сульфат натрия, обеспечивающие нейтральную среду растворов. Выбор этих солей обусловлен наличием в них электрохимически неактивного в исследуемых условиях аниона, являющегося конечным продуктом окисления тиосульфатионов $\left(\mathrm{Na}_{2} \mathrm{SO}_{4}\right)$, или слабо адсорбирующегося аниона
$\left(\mathrm{KNO}_{3}\right)$, не обладающего комплексообразующими свойствами по отношению к компонентам исследуемой системы. На основании предварительной регистрации циклических вольтамперограмм (ЦВА) электрода АиУКЭ в 0,01-0,5 М растворах фоновых электролитов в присутствии $1 \cdot 10^{-4} \mathrm{M} \mathrm{Na}_{2} \mathrm{~S}_{2} \mathrm{O}_{3}$ показано, что оптимальной концентрацией фонового электролита является 0,05 М. При меньшей концентрации фона возрастает сопротивление раствора, при более высокой концентрации происходит снижение тока электродного процесса с участием $\mathrm{S}_{2} \mathrm{O}_{3}{ }^{2-}$-ионов.

Из данных ЦВА следует, что анодное окисление $\mathrm{S}_{2} \mathrm{O}_{3}{ }^{2-}$-ионов на АиУКЭ включает два процесса при $E=0,1 \ldots 0,6 \quad$ В $\left(E_{\mathrm{p}, 1} \approx 0,35\right.$ В $)$ и при $E=0,8 \ldots 1,3$ В $\left(E_{\mathrm{p}, 2} \approx 1,1\right.$ В) (рис. 2). Соответствующие анодным токам процессы катодного восстановления не выражены, величины катодного тока в растворах, содержащих $\mathrm{S}_{2} \mathrm{O}_{3}{ }^{2-}$-ионы, незначительно отличаются от таковых для фоновых электролитов. По-видимому, рассматриваемые процессы являются необратимыми вследствие образования продуктов окисления тиосульфата, не восстанавливающихся при данных потенциалах.

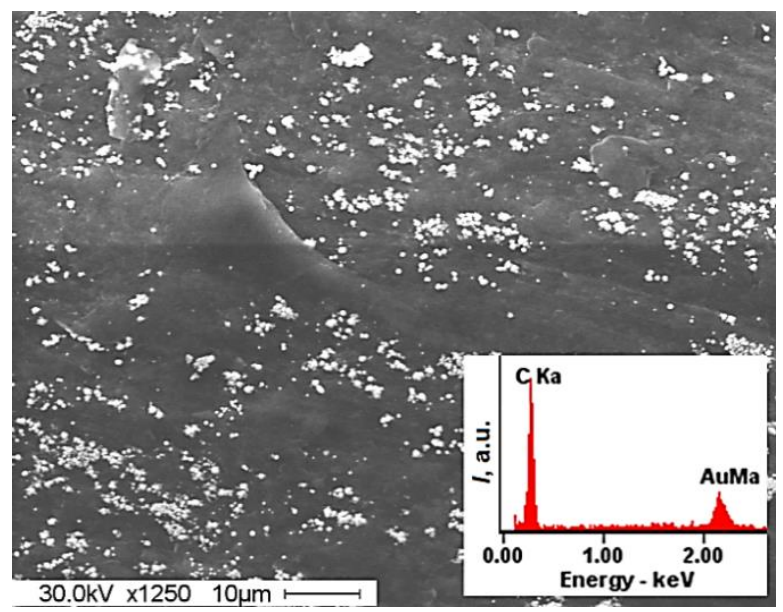

Pис. 1. Микрофотография поверхности модифицированного частииами золота углеродсодержащего композитного электрода АиУКЭ; на врезке - характеристический рентгеновский спектр участка поверхности модифицированного электрода

Fig. 1. Micrograph of the surface of a carbon-containing composite electrode modified with gold particles $A u C C E$; the inset shows the characteristic $X$-ray spectrum of the surface area of the modified electrode

Влияние условий регистрации вольтамперограмм на величины анодных токов $I_{\mathrm{p}, 1}$ и $I_{\mathrm{p}, 2}$ оценивали путем изменения начального потенциала регистрации, присутствия растворенного кислорода, скорости развертки потенциалов. Варьирование диапазона потенциалов показало, что оптимальным потенциалом начала регистрации является $E_{\mathrm{H}}=0,0$ В. При более положи-

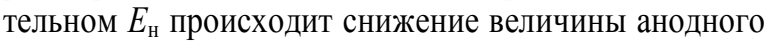
тока в области $0,8 \ldots 1,3 \mathrm{~B}$, использование более отрицательных потенциалов $E_{\text {н }}$ приводит к протеканию 
побочных процессов восстановления. Присутствие кислорода в растворе приводит к существенному увеличению погрешности определения $\mathrm{S}_{2} \mathrm{O}_{3}{ }^{2-}$-ионов по предлагаемому методу, в ходе анализа процедура деаэрирования раствора азотом (аргоном) является обязательной. Влияние скорости развертки потенциалов $(v=40 \ldots 180 \mathrm{MB} / \mathrm{c})$ на величины анодных токов изуча- ли в растворе $1 \cdot 10^{-4} \mathrm{M} \mathrm{S}_{2} \mathrm{O}_{3}{ }^{2-}$-ионов на фоне $0,05 \mathrm{M}$ $\mathrm{KNO}_{3}$. При $v>100 \mathrm{mB} / \mathrm{c}$ максимум анодного тока при $0,8 \ldots 1,3$ В существенно искажается, что затрудняет измерение аналитического сигнала; при меньших $v$ значения $I_{\mathrm{p}}$ уменьшаются. В связи с этим дальнейшие измерения аналитических сигналов $I_{\mathrm{p}, 1}$ и $I_{\mathrm{p}, 2}$ проводили при скорости развертки $100 \mathrm{MB} / \mathrm{c}$.
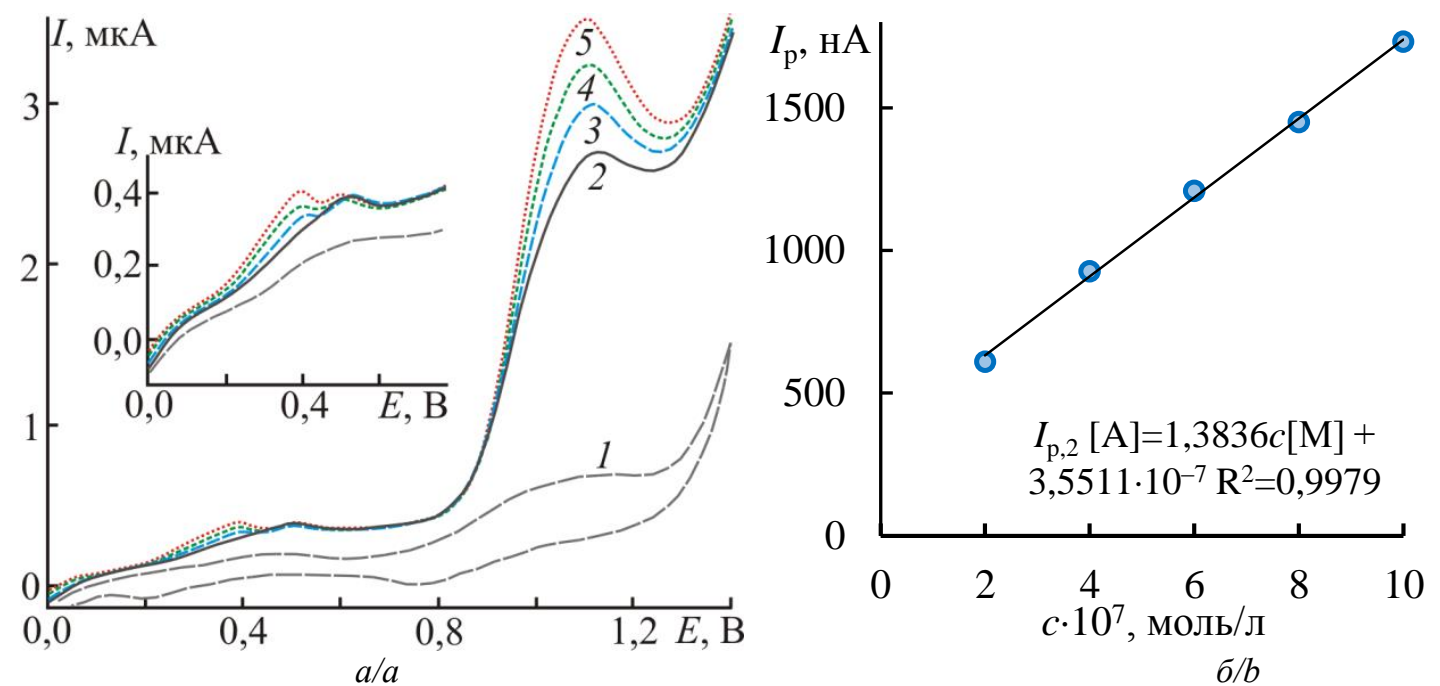

Pис. 2. а) вольтамперограммы модифицированного электрода АиУКЭ в растворах 0,05 $\mathrm{M} \mathrm{Na}_{2} \mathrm{SO}_{4}+\mathrm{Na}_{2} \mathrm{~S}_{2} \mathrm{O}_{3}$ $\left(E_{\text {нач }}=0,0 \mathrm{~B}, E_{\text {кон }}=1,4 \mathrm{~B}, v=100 \mathrm{MB} / \mathrm{c}, \mathrm{pH}=7\right.$, деаэрирование растворов азотом) при различных концентрациях тиосульфата натрия, М: 1) фоновая кривая; 2) $2 \cdot 10^{-7}$; 3) $4 \cdot 10^{-7}$; 4) $6 \cdot 10^{-7}$; 5) $8 \cdot 10^{-7}$; на врезке - участки вольтамперограмм в интервале потенциалов $0,0 \ldots 0,6 \mathrm{~B}$; б) зависимость тока окисления $I_{p, 2}$ nри $E_{p, 2} \approx 1,1 \mathrm{~B}$ от концентрации $\mathrm{S}_{2} \mathrm{O}_{3}{ }^{2-}$-ионов в растворе (фоновый электролит 0,05 $\mathrm{M} \mathrm{Na}_{2} \mathrm{SO}_{4}$ )

Fig. 2. a) voltammograms of the modified AuCCE electrode in solutions of $0,05 \mathrm{M} \mathrm{Na}_{2} \mathrm{SO}_{4}+\mathrm{Na}_{2} \mathrm{~S}_{2} \mathrm{O}_{3}\left(E_{\text {init }}=0,0 \mathrm{~V}, E_{\text {final }}=1,4 \mathrm{~V}\right.$, $v=100 \mathrm{mV} / \mathrm{s}, \mathrm{pH}=7$, solutions were deaerated with nitrogen) at different concentrations of sodium thiosulfate, M: 1) the blank curve; 2) $2 \cdot 10^{-7}$; 3) $4 \cdot 10^{-7}$; 4) $6 \cdot 10^{-7}$; 5) $8 \cdot 10^{-7}$; the inset shows a section of voltammograms in the potential range of $0,0 \ldots 0,6 \mathrm{~V} ; b)$ the dependence of the oxidation current $I_{p, 2}$ at $E_{p, 2} \approx 1,1 \mathrm{~V}$ on concentration of $\mathrm{S}_{2} \mathrm{O}_{3}{ }^{2-}$ ions in solutions (supporting electrolyte $0,05 \mathrm{M} \mathrm{Na}_{2} \mathrm{SO}_{4}$ )

Величина тока $I_{\mathrm{p}, 1}$ в области потенциалов $E_{\mathrm{p}, 1} \approx 0,3 \ldots 0,4$ В достигает на порядок меньших значений по сравнению со вторым анодным максимумом $I_{\mathrm{p}, 2}$ при $E_{\mathrm{p}, 2} \approx 1,1$ В (рис. 2). Параметры первого анодного процесса $\left(E_{\mathrm{p}, 1}, I_{\mathrm{p}, 1}\right)$ изменяются в зависимости от состава фонового электролита и концентрации $\mathrm{S}_{2} \mathrm{O}_{3}{ }^{2-}$ ионов в растворе. В фоновом электролите $\mathrm{Na}_{2} \mathrm{SO}_{4}$ первый максимум анодного тока включает две волны при $E \approx 0,4$ и 0,5 В (рис. 2,a); в растворе $\mathrm{KNO}_{3}$ первый максимум не содержит второй волны (рис. $3, a$ ), при концентрациях $\mathrm{S}_{2} \mathrm{O}_{3}{ }^{2-}$-ионов ниже $10^{-6} \mathrm{M}$ этот максимум практически не проявляется (табл. 1).

Изучение влияния концентрации $\mathrm{S}_{2} \mathrm{O}_{3}{ }^{2-}$-ионов на параметры анодного тока показало, что зависимости $I_{\mathrm{p}}=f(c)$ как для первого $I_{\mathrm{p}, 1}$, так и второго $I_{\mathrm{p}, 2}$ анодного тока являются линейными в определенных концентрационных диапазонах (рис. 2, б, 3, б). Линейная зависимость для $I_{\mathrm{p}, 1}$ соблюдается в относительно узком диапазоне концентраций тиосульфата $1 \cdot 10^{-6} \ldots 1 \cdot 10^{-5}$ М и описывается уравнением (рис. 3, б):

$$
I_{\mathrm{p}, 1}[\mathrm{~A}]=0,0393 c[\mathrm{M}]+1,0210 \cdot 10^{-7}\left(\mathrm{R}^{2}=0,9976\right) .
$$

Аналогичная зависимость для $I_{\mathrm{p}, 2}$ является линейной в более широком интервале концентраций $1 \cdot 10^{-7} \ldots 1 \cdot 10^{-5} \mathrm{M} \mathrm{и} \mathrm{описывается} \mathrm{уравнением} \mathrm{(рис.} \mathrm{2,} \mathrm{б):}$

$$
I_{\mathrm{p}, 2}[\mathrm{~A}]=1,3836 c[\mathrm{M}]+3,5511 \cdot 10^{-7}\left(\mathrm{R}^{2}=0,9979\right) .
$$

Из сопоставления приведенных регрессионных уравнений (1), (2) следует, что концентрационная зависимость для $I_{\mathrm{p}, 1}$ характеризуется меньшим на два порядка угловым коэффициентом (чувствительностью) по сравнению с таковым для $I_{\mathrm{p}, 2}$ при более высоких потенциалах.

С целью определения причин различной формы максимумов первого и второго анодного токов, а также различной величины этих сигналов при одинаковом содержании анализируемого вещества в растворе были проведены расчеты зависимостей равновесных активностей ионно-молекулярных форм серы, участвующих в электродных процессах, от потенциала (ст. в. э.) с учётом начальной концентрации $\mathrm{S}_{2} \mathrm{O}_{3}{ }^{2-}$ ионов. Вычисления проводили при помощи программного пакета Chemical Equilibrium Diagrams. Расчетная диаграмма для системы $\mathrm{S}-\mathrm{H}_{2} \mathrm{O}$ представлена на рис. 4, a. Из диаграммы следует, что при заданном значении $\mathrm{pH}=7$ основными устойчивыми серосодержащими формами в водном растворе являются сероводород при потенциалах отрицательнее $-0,2 \mathrm{~B}$, элементная сера в интервале потенциалов $(0,4 \ldots 0,15)$ В с максимальной активностью при $-0,22$ В 
и сульфат-ионы при потенциалах положительнее 0,15 В. В области потенциала $-0,22$ В возможно образование следовых количеств полисульфидов с активностями на уровне $10^{-11}$ моль/л (на диаграмме не показаны). При заданных условиях расчёта равновесная концентрация тиосульфат-ионов также низка и находится на уровне $10^{-10}$ моль/л при $E=-0,22 \mathrm{~B}$, что свидетельствует о метастабильности тиосульфата по сравнению с отображёнными на диаграмме серосодержащими соединениями.
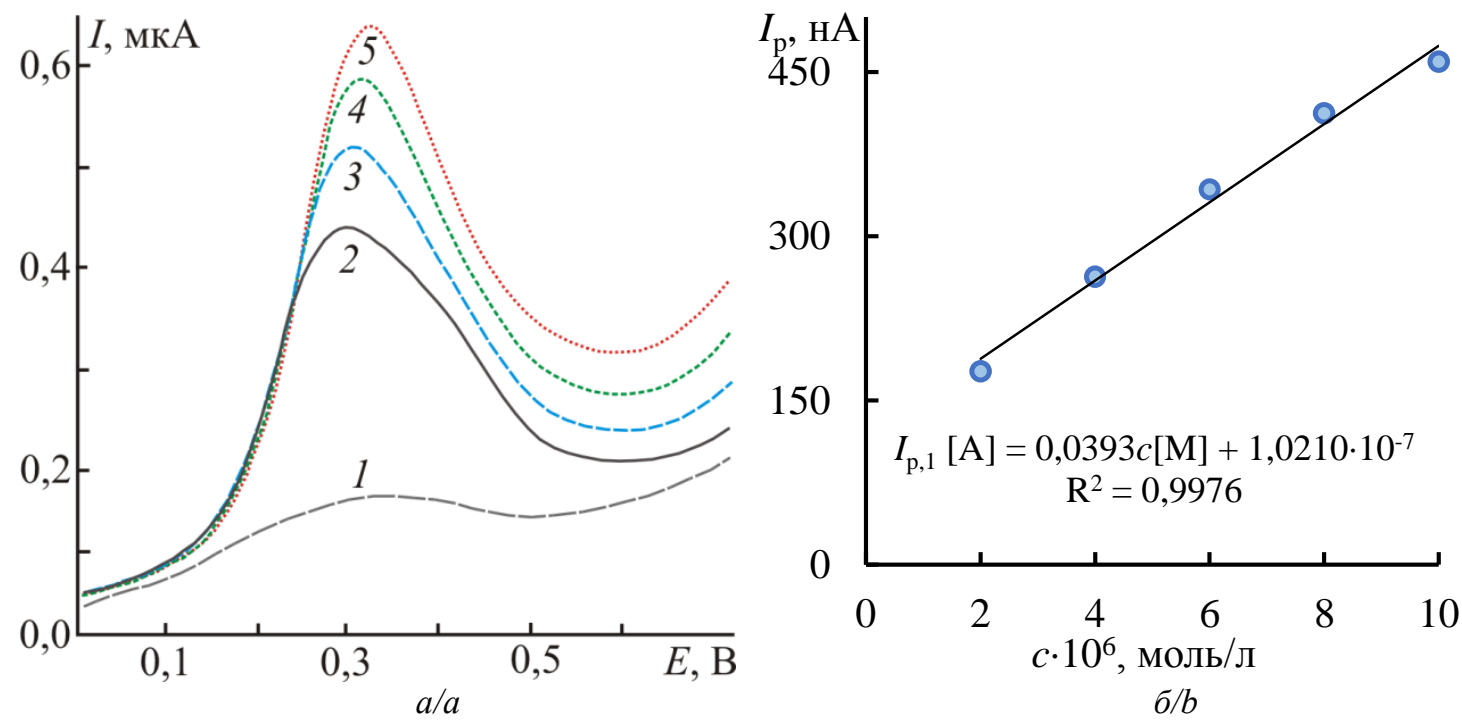

Pис. 3. а) вольтамперограммы модифицированного электрода АиУКЭ в растворах 0,05 $\mathrm{M} \mathrm{KNO}_{3}+\mathrm{Na}_{2} \mathrm{~S}_{2} \mathrm{O}_{3}\left(E_{\text {нач }}=0,0 \mathrm{~B}\right.$, $E_{к о н}=0,6 \mathrm{~B}, v=100 \mathrm{mB} / \mathrm{c}, \mathrm{pH}=7$, деаэрирование растворов азотом) при различных концентрачиях тиосульфата натрия, М: 1) фоновая кривая; 2) $2 \cdot 10^{-6}$; 3) $4 \cdot 10^{-6}$; 4) $6 \cdot 10^{-6}$; 5) $8 \cdot 10^{-6}$; б) зависимость тока окисления $I_{p, 1}$ при $E_{p, 1} \approx 0,3$ В от концентрации $\mathrm{S}_{2} \mathrm{O}_{3}{ }^{2-}$-ионов в растворе (фоновый электролит 0,05 $\mathrm{M} \mathrm{KNO}_{3}$ )

Fig. 3. a) voltammograms of the modified AuCCE electrode in solutions of $0,05 \mathrm{M} \mathrm{KNO}_{3}+\mathrm{Na}_{2} \mathrm{~S}_{2} \mathrm{O}_{3}\left(E_{\text {init }}=0,0 \mathrm{~V}, E_{\text {final }}=0,6 \mathrm{~V}\right.$, $v=100 \mathrm{mV} / \mathrm{s}, \mathrm{pH}=7$, solutions were deaerated with nitrogen) at different concentrations of sodium thiosulfate, M: 1) the blank curve; 2) $2 \cdot 10^{-6}$; 3) $4 \cdot 10^{-6}$; 4) $6 \cdot 10^{-6}$; 5) $8 \cdot 10^{-6}$; b) the dependence of the oxidation current $I_{p, 1}$ at $E_{p, 1} \approx 0,3 \mathrm{~V}$ on concentration of $\mathrm{S}_{2} \mathrm{O}_{3}{ }^{2-}$ ions in solutions (supporting electrolyte 0,05 $\mathrm{M} \mathrm{KNO}_{3}$ )
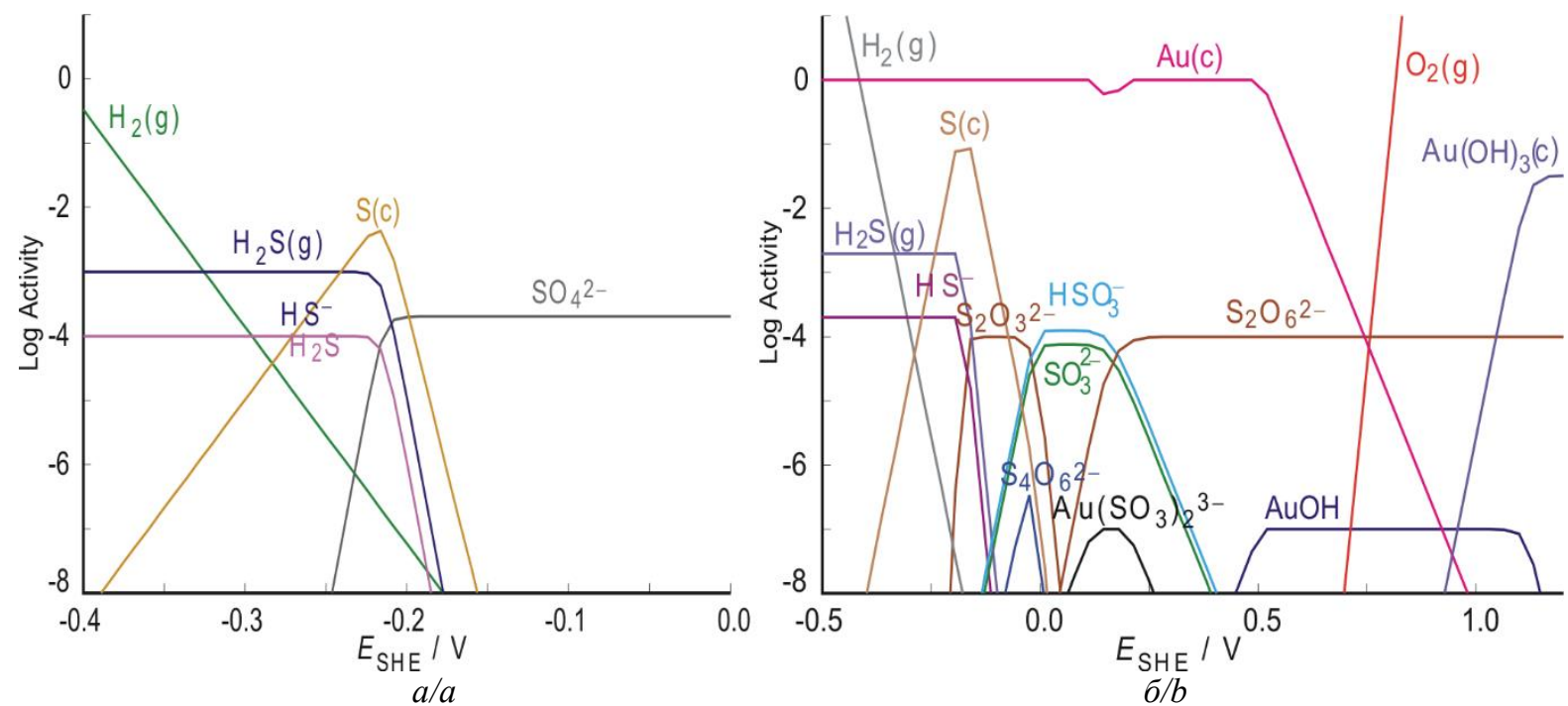

Pис. 4. Расчётные диаграммы «активность-потенииал» а) равновесных ионно-молекулярных форм в системе $\mathrm{S}-\mathrm{H}_{2} \mathrm{O}$ и б) метастабильных ионно-молекулярных форм (при отсутствии $\mathrm{SO}_{4}{ }^{2-}$-ионов) в системе $\mathrm{S}-\mathrm{Au}-\mathrm{H}_{2} \mathrm{O}$ при $\mathrm{pH}=7,[\mathrm{~S}]_{\text {cys }}=1 \cdot 10^{-4} \mathrm{M},[\mathrm{Au}]_{\text {cys }}=1 \cdot 10^{-7} \mathrm{M}, t=25^{\circ} \mathrm{C}$

Fig. 4. Calculated diagrams «activity-potential» a) for equilibrium ion-molecular species in the $\mathrm{S}-\mathrm{H}_{2} \mathrm{O}$ system and b) for metastable ion-molecular species (in the absence of $\mathrm{SO}_{4}{ }^{2-}$ ions) in the $\mathrm{S}-\mathrm{Au}-\mathrm{H}_{2} \mathrm{O}$ system at $\mathrm{pH}=7,[\mathrm{~S}]_{\text {tot }}=1 \cdot 10^{-4} \mathrm{M}$, $[A u]_{\text {tot }}=1 \cdot 10^{-7} \mathrm{M}, t=25^{\circ} \mathrm{C}$

Из анализа диаграммы (рис. 4, a) следует, что при потенциалах положительнее $-0,15$ В в системе не должны протекать процессы окисления по причине отсутствия в ней способных окисляться ионномолекулярных форм. По-видимому, фиксируемые на вольтамперограммах анодные токи при потенциалах 
$0,1 \ldots 0,6$ и $0,8 \ldots 1,3$ В (х. с. э.) связаны с участием в электродном процессе промежуточных продуктов окисления тиосульфат-ионов. Считают [25], что продуктом непосредственного окисления $\mathrm{S}_{2} \mathrm{O}_{3}{ }^{2-}$-ионов на $\mathrm{Au-электроде} \mathrm{являются} \mathrm{тетратионат-ионы.} \mathrm{Процесс}$ при $\mathrm{pH \approx 7}$ протекает в области потенциалов $0,1 \ldots 0,3$ В (ст. в. э.), является необратимым с наложением химической стадии, сопровождается образованием серы и осложняется растворением металла с образованием комплексов $[25,26]$. Вместе с тем потенциалы образования $\mathrm{S}_{4} \mathrm{O}_{6}{ }^{2-}$-ионов также существенно ниже наблюдаемых в эксперименте.

Таблица 1. Потенииаль максимумов анодных токов окисления тиосульфат-ионов на модифици рованном электроде АиУКЭ в различных фоновых электролитах $\left(E_{\text {нач }}=0,0 \mathrm{~B}, E_{\text {кон }}=1,4 \mathrm{~B}\right.$ $v=100 \mathrm{MB} / \mathrm{c}, \mathrm{pH}=7$, деаэрирование растворов азотом)

Table 1. Peak potentials of anodic oxidation of thiosulfate ions at the modified electrode $A u C C E$ in different supporting electrolytes $\left(E_{\text {init }}=0,0 \mathrm{~V}, E_{\text {final }}=1,4 \mathrm{~V}, v=100 \mathrm{mV} / \mathrm{s}, \mathrm{pH}=7\right.$, solutions were deaerated with nitrogen)

\begin{tabular}{|c|c|c|c|}
\hline \multirow{2}{*}{$c\left(\mathrm{Na}_{2} \mathrm{~S}_{2} \mathrm{O}_{3}\right), \mathrm{M}$} & \multicolumn{2}{|c|}{$0,05 \mathrm{MNO}_{3}$} & $0,05 \mathrm{M} \mathrm{Na}_{2} \mathrm{SO}_{4}$ \\
\cline { 2 - 4 } & $E_{\mathrm{p}, 1}$ & $E_{\mathrm{p}, 2}$ & $E_{\mathrm{p}, 2}$ \\
\hline $1 \cdot 10^{-7}$ & - & 1,04 & 1,07 \\
\hline $2 \cdot 10^{-7}$ & - & 1,05 & 1,07 \\
\hline $4 \cdot 10^{-7}$ & - & 1,06 & 1,07 \\
\hline $6 \cdot 10^{-7}$ & - & 1,06 & 1,07 \\
\hline $8 \cdot 10^{-7}$ & - & 1,06 & 1,07 \\
\hline $1 \cdot 10^{-6}$ & 0,38 & 1,07 & 1,07 \\
\hline $2 \cdot 10^{-6}$ & 0,37 & 1,08 & 1,07 \\
\hline $4 \cdot 10^{-6}$ & 0,29 & 1,10 & 1,07 \\
\hline $6 \cdot 10^{-6}$ & 0,29 & 1,13 & 1,08 \\
\hline $8 \cdot 10^{-6}$ & 0,29 & 1,16 & 1,10 \\
\hline $1 \cdot 10^{-5}$ & 0,29 & 1,22 & 1,11 \\
\hline $2 \cdot 10^{-5}$ & 0,29 & 1,24 & - \\
\hline $4 \cdot 10^{-5}$ & 0,28 & - & - \\
\hline $6 \cdot 10^{-5}$ & 0,27 & - & - \\
\hline $8 \cdot 10^{-5}$ & 0,27 & - & - \\
\hline $1 \cdot 10^{-4}$ & 0,27 & - & - \\
\hline $2 \cdot 10^{-4}$ & 0,27 & - & - \\
\hline & & & \\
\hline
\end{tabular}

Для определения термодинамически вероятных промежуточных продуктов окисления тиосульфата из набора кислотно-основных и окислительновосстановительных равновесий были исключены реакции с участием сульфат-ионов. Полученная расчётная диаграмма метастабильных форм в системе $\mathrm{S}$ $\mathrm{Au}-\mathrm{H}_{2} \mathrm{O}$ с низкими степенями окисления серы приведена на рис. 4, б. Диаграмма содержит несколько промежуточных соединений со степенью окисления серы ниже +6 (отсутствуют на равновесной диаграмме, рис. $4, a$ ) с различными интервалами потенциалов устойчивости: тиосульфат- $(-0,2 \ldots-0,05$ B), тетратионат- $(-0,08 \ldots 0,0$ В), гидросульфит- $(-0,12 \ldots 0,4$ В) и дитионат-ионы (положительнее 0,05 В). Расчетные активности гидросульфит- и дитионат-ионов в растворе принимают значения одного порядка, при этом активность тетратионат-ионов на два порядка ниже. Нужно отметить, что область устойчивости элементной серы в этих условиях существенно смещена в сторону положительных потенциалов по сравнению с диаграммой равновесных форм с участием $\mathrm{SO}_{4}{ }^{2-}$ ионов (рис. $4, a$ ). Для золота на диаграмме (рис. 4, б) отмечен эффект растворения в области потенциалов $0,1 \ldots 0,2 \mathrm{~B}$ с образованием комплексов $\left[\mathrm{Au}\left(\mathrm{SO}_{3}\right)_{2}\right]^{3-}$ $\left(\mathrm{p} K_{\mathrm{H}} \approx 27\right)$ и $\left[\mathrm{Au}\left(\mathrm{S}_{2} \mathrm{O}_{3}\right)_{2}\right]^{3-}\left(E^{\circ}=0,15 \mathrm{~B}, \mathrm{p} K_{\mathrm{H}}=26\right.$ [27] $)$, устойчивость которых сравнима с устойчивостью аналогичных комплексов ртути. Активность сульфитного комплекса существенно выше, чем тиосульфатного, вследствие окисления последнего в рассматриваемой области потенциалов [27]. В соответствии с расчетными данными при фиксируемом потенциале начала анодного окисления $0,1 \mathrm{~B}$ (рис. $3, a)$ должны преобладать процессы с участием $\mathrm{SO}_{3}{ }^{2-}$-ионов и частиц Аu.

Из данных Раман-спектроскопии известно [25, 26], что при контакте золота с растворами тиосульфатов при отсутствии внешней поляризации на поверхности металла формируется адсорбционный слой серы. При анодной поляризации до 0,4 В (ст. в. э.) на поверхности золота формируется тонкий слой сульфидов и начинают адсорбироваться тетратионат-ионы. После появления тетратионат-ионов интенсивность сигнала от сульфидов золота начинается ослабевать, этот сигнал исчезает при 0,56 В. При этом потенциале начинается катенация серы с образованием поверхностного полимеризованного слоя, который приводит к пассивации Au-электрода при достижении потенциала $0,6 \mathrm{~B}[25]$.

На основании результатов расчётов (рис. 4) и литературных данных [25-28] анодный процесс в области потенциалов $E_{\mathrm{p}, 1}=0,2 \ldots 0,6 \mathrm{~B}$ (рис. 2,3 ) можно интерпретировать следующим образом. Незначительное увеличение анодного тока на вольтамперограмме в области потенциалов $0,05 \ldots 0,2$ В (рис. $2, a$ ) соответствует началу анодной поляризации электрода от стационарного потенциала ( 0,05 В) до начала интенсивного повышения анодного тока. В этом диапазоне потенциалов протекает несколько параллельных процессов: хемосорбция тиосульфат-ионов с образованием сульфидного субмонослоя, а также сульфит-ионов; растворение золота с образованием тиосульфатного комплекса и его частичное окисление до сульфитного; окисление тиосульфат-ионов с образованием тетратионат-ионов:

$$
\begin{aligned}
& \mathrm{Au}+\mathrm{S}_{2} \mathrm{O}_{3}{ }^{2-} \rightarrow \mathrm{Au}-\mathrm{S}_{\mathrm{ad}}+\mathrm{SO}_{3}{ }^{2-} ; \\
& \mathrm{Au}+2 \mathrm{~S}_{2} \mathrm{O}_{3}{ }^{2-} \rightarrow\left[\mathrm{Au}\left(\mathrm{S}_{2} \mathrm{O}_{3}\right)_{2}\right]^{3-}+\mathrm{e} ; \\
& 2 \mathrm{~S}_{2} \mathrm{O}_{3}{ }^{2-} \rightarrow \mathrm{S}_{4} \mathrm{O}_{6}{ }^{2-}+2 \mathrm{e} ; \\
& \mathrm{S}_{2} \mathrm{O}_{3}{ }^{2-}+3 \mathrm{H}_{2} \mathrm{O} \rightarrow 2 \mathrm{HSO}_{3}{ }^{-}+4 \mathrm{H}^{+}+4 \mathrm{e} .
\end{aligned}
$$

Результатом протекания совокупности процессов (3)-(6) является образование на поверхности $\mathrm{Au}$ хемосорбированной (сульфидной) серы, а также сульфит- и тетратионат-ионов. Накопление этих промежуточных продуктов приводит к повышению анодного тока в интервале потенциалов $0,2 \ldots 0,6$ В, отображающегося на вольтамперограмме в виде двух волн $\left(E_{\max } \approx 0,35\right.$ и 0,5 В) при относительно высокой концентрации тиосульфат-ионов в растворе порядка $10^{-4} \mathrm{M}$ (рис. 2, a). В области первой волны происходит окисление хемосорбированной серы и тетратионат-ионов: 


$$
\begin{gathered}
\mathrm{Au}-\mathrm{S}_{\mathrm{ad}}+3 \mathrm{H}_{2} \mathrm{O} \rightarrow \mathrm{Au}+\mathrm{HSO}_{3}^{-}+5 \mathrm{H}^{+}+4 \mathrm{e} ; \\
\mathrm{S}_{4} \mathrm{O}_{6}{ }^{2-}+6 \mathrm{H}_{2} \mathrm{O} \rightarrow 4 \mathrm{HSO}_{3}^{-}+8 \mathrm{H}^{+}+6 \mathrm{e} .
\end{gathered}
$$

При потенциале второй волны ( 0,5 В) происходит окисление сульфита:

$$
2 \mathrm{SO}_{3}{ }^{2-} \rightarrow \mathrm{S}_{2} \mathrm{O}_{6}{ }^{2-}+2 \mathrm{e} \text {. }
$$

При заданных условиях эксперимента образующиеся дитионат-ионы в электродных и химических стадиях не участвуют. Возможность использования величины анодного тока при $E \approx 0,5$ В (х. с. э.) в аналитических целях для определения сульфита по реакции (9) продемонстрирована в работе [29]. Накопление в системе высокореакционноспособных промежуточных продуктов окисления тиосульфата, образующихся в результате протекания электродных реакций (4)-(9), инициирует ряд побочных реакций с участием политионатов, разложение которых приводит к образованию серы:

$$
\begin{gathered}
\mathrm{S}_{2} \mathrm{O}_{3}{ }^{2-}+\mathrm{HSO}_{3}{ }^{-} \rightarrow \mathrm{S}_{3} \mathrm{O}_{6}{ }^{2-}+\mathrm{H}^{+}+2 \mathrm{e} ; \\
\mathrm{S}_{4} \mathrm{O}_{6}{ }^{2-}+\mathrm{HSO}_{3} \rightarrow \rightarrow \mathrm{S}_{2} \mathrm{O}_{3}{ }^{2-}+\mathrm{S}_{3} \mathrm{O}_{6}{ }^{2-}+\mathrm{H}^{+} ; \\
\mathrm{S}_{3} \mathrm{O}_{6}{ }^{2-}+\mathrm{H}_{2} \mathrm{O} \rightarrow \mathrm{SO}_{4}{ }^{2-}+\mathrm{HSO}_{3}{ }^{-}+\mathrm{S}+\mathrm{H}^{+} .
\end{gathered}
$$

Необходимо отметить, что протекание химических и электродных реакций (6)-(8), (10)-(12) сопровождается подкислением среды прианодного слоя раствора, что также способствует образованию серы за счет разложения тиосульфата. Осаждение серы на поверхности электрода сопровождается её катенацией с образованием полимеризованного слоя, пассивирующего поверхность $\mathrm{Au}$ (рис. 3, a). Эффект пассивации Аu-электрода в сходных экспериментальных условиях наблюдали в работах $[25,26]$. Таким образом, процесс окисления тиосульфат-ионов в области потенциалов 0,2...0,6 В может быть представлен в виде суммарного уравнения (13), содержащего устойчивые в условиях эксперимента ионно-молекулярные формы серы:

$$
\mathrm{S}_{2} \mathrm{O}_{3}{ }^{2-}+\mathrm{H}_{2} \mathrm{O} \rightarrow \mathrm{S}+\mathrm{SO}_{4}{ }^{2-}+2 \mathrm{H}^{+}+2 \mathrm{e} .
$$

Из анализа совокупности электродных и химических реакций, протекающих на АиУКЭ в области потенциалов $E<0,6 \mathrm{~B}$, следует, что аналитический сигнал $I_{\mathrm{p}, 1}$ зависит от большого числа трудно контролируемых факторов, прежде всего от концентрации и стабильности образующихся промежуточных продуктов окисления тиосульфат-ионов и степени блокирования активной поверхности частиц золота осадком серы. Эти особенности позволяют объяснить достаточно узкий концентрационный диапазон, в котором зависимость $I_{\mathrm{p}, 1}=f\left[c\left(\mathrm{Na}_{2} \mathrm{~S}_{2} \mathrm{O}_{3}\right)\right]$ является линейной, a также низкое значение углового коэффициента концентрационной зависимости (рис. 3, б). Следовательно, использование тока анодного окисления $I_{\mathrm{p}, 1}$ при $E<0,6$ В для определения тиосульфат-ионов нецелесообразно.

В отличие от первого анодного максимума, анодный ток $I_{\mathrm{p}, 2}$ в интервале потенциалов $0,8 \ldots 1,3$ В характеризуется на порядок большими значениями (рис. 2, $a)$, зависимость $I_{\mathrm{p}, 2}=f\left[c\left(\mathrm{Na}_{2} \mathrm{~S}_{2} \mathrm{O}_{3}\right)\right]$ является линейной в широком интервале концентраций $\mathrm{S}_{2} \mathrm{O}_{3}{ }^{2-}$ ионов $1 \cdot 10^{-7} \ldots 1 \cdot 10^{-5} \mathrm{M}$ и характеризуется высоким значением углового коэффициента (рис. 2, б). Из ре- зультатов работы [30] по анодному окислению осажденных на поверхность золота плёнок серы следует, что при данных условиях основной электродной реакцией является окисление серы до сульфат-ионов:

$$
\mathrm{S}+4 \mathrm{H}_{2} \mathrm{O} \rightarrow \mathrm{SO}_{4}{ }^{2-}+8 \mathrm{H}^{+}+6 \mathrm{e} .
$$

Существенное повышение тока $I_{\mathrm{p}, 2}$ по сравнению с $I_{\mathrm{p}, 1}$ при одной и той же концентрации $\mathrm{S}_{2} \mathrm{O}_{3}{ }^{2-}$-ионов в растворе свидетельствует, с одной стороны, о значительном накоплении серы на поверхности частиц $\mathrm{Au}$ за время нарастания потенциала в условиях линейной поляризации, с другой - об электрокаталитической природе процесса (14). Действительно, при $E>0,8$ В происходит формирование метастабильных (гидр)оксидов золота [31] в качестве медиаторов по реакции (15), обусловливающих повышение величины анодного тока за счет каталитической составляющей электродного процесса:

$$
\begin{gathered}
\mathrm{Au}+x \mathrm{H}_{2} \mathrm{O} \rightarrow \mathrm{Au}(\mathrm{OH})_{x}+x \mathrm{H}^{+}+x \mathrm{e} ; \\
\mathrm{Au}(\mathrm{OH})_{x}+1 / 4 x \mathrm{~S} \rightarrow \mathrm{Au}+1 / 4 x \mathrm{SO}_{4}{ }^{2-}+x \mathrm{H}^{+} .
\end{gathered}
$$

Очевидно, что доля каталитического тока существенно возрастает за счет участия в процессе окисления частиц золота наноразмерного диапазона (рис. 1). Таким образом, анодный ток в области потенциалов $0,8 \ldots 1,3$ В может быть использован в качестве аналитического сигнала для определения достаточно низких концентраций тиосульфат-ионов. Чувствительность метода повышается за счет накопления серы на поверхности частиц $\mathrm{Au}$ вследствие протекания электродных и химических реакций с участием многочисленных промежуточных продуктов окисления $\mathrm{S}_{2} \mathrm{O}_{3}{ }^{2-}$-ионов, каталитической составляющей тока, а также малых размеров (высокой площади удельной поверхности) частиц Аu.

Для уточнения влияния массопереноса на анодный процесс была изучена зависимость величины тока $I_{\mathrm{p}, 2}$ от скорости развертки потенциалов $v$. Из полученных данных следует (рис. 5), что зависимость $I_{\mathrm{p}, 2}=f(v)$ является линейной как от скорости, так и от корня квадратного из скорости развертки потенциалов. По этому признаку, а также по отсутствию на ЦВА катодных токов, соответствующих рассматриваемым анодным токам, и по линейной зависимости $E_{\mathrm{p}}-\lg v$ электродный процесс является необратимым, содержит замедленную стадию диффузии и сопровождается поверхностной реакцией. Образование пассивирующего слоя серы на поверхности частиц $\mathrm{Au}$ и протекание поверхностной химической реакции (16) согласуются с этим заключением.

Стабильность работы модифицированного электрода АиУКЭ при продолжительном использовании без обновления его поверхности изучали путем многократной регистрации вольтамперограмм в раствоpax $0,05 \mathrm{M} \mathrm{KNO}_{3}+1 \cdot 10^{-4} \mathrm{M} \mathrm{Na}_{2} \mathrm{~S}_{2} \mathrm{O}_{3}$ с последующим измерением количества электричества, прошедшего через электрод при поляризации в $0,05 \mathrm{M} \mathrm{H}_{2} \mathrm{SO}_{4}$ до более высоких положительных потенциалов $E_{\text {кон }}=1,5 \mathrm{~B}$ (рис. 6). Из результатов измерений следует, что многократная регистрация аналитического сигнала (1000 раз) приводит к снижению активной поверхно- 
сти электрода на 20\%. Следовательно, при протекании электродных реакций дисперсность частиц $\mathrm{Au}$ и структура их поверхностного слоя не подвергаются существенным изменениям, электрод может быть многократно использован для регистрации сигнала без обновления поверхности.
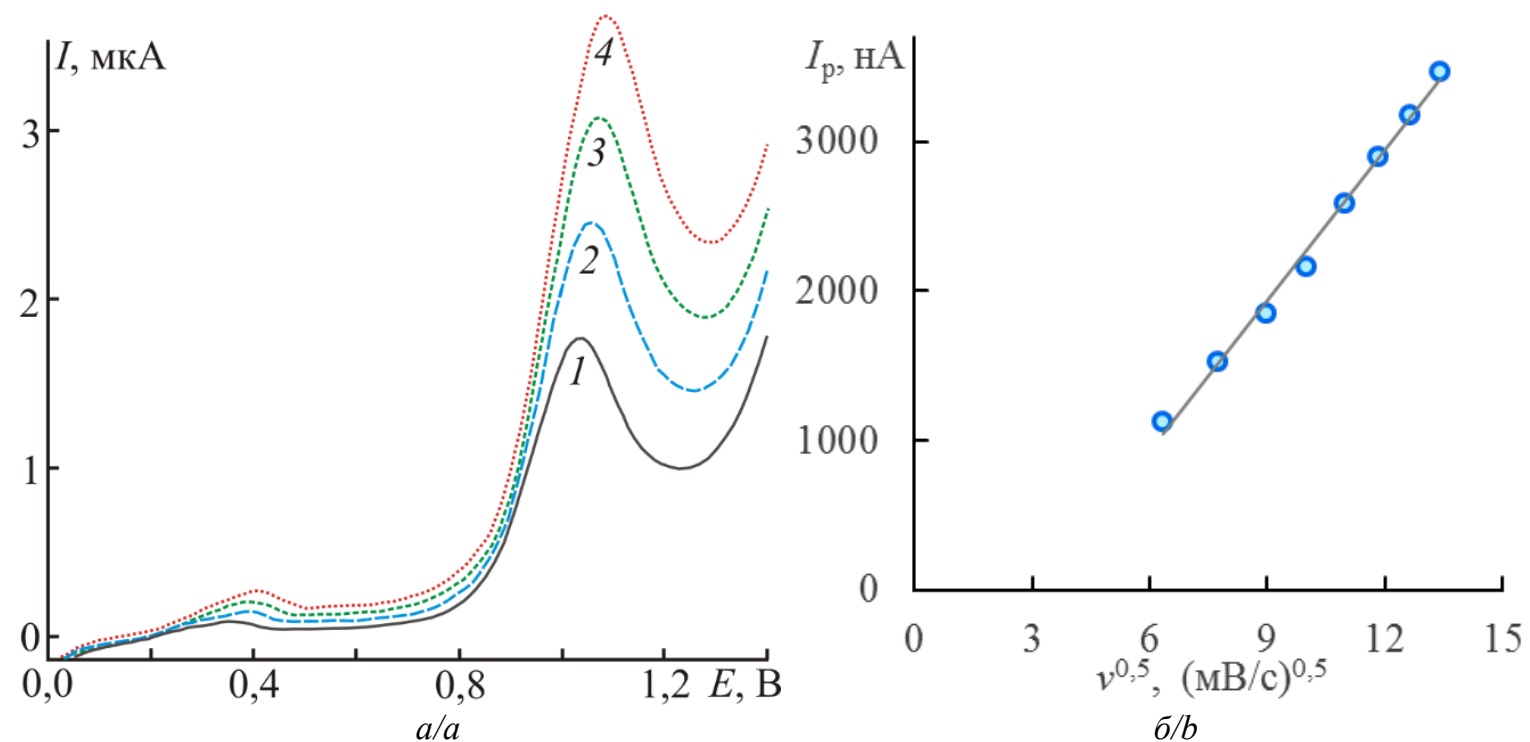

Pис. 5. а) вольтамперограммы модифицированного электрода АиУКЭ в растворе 0,05 $\mathrm{M} \mathrm{Na}_{2} \mathrm{SO}_{4}+1 \cdot 10^{-4} \mathrm{M} \mathrm{Na}_{2} \mathrm{~S}_{2} \mathrm{O}_{3}$ $\left(E_{\text {нач }}=0,0 \mathrm{~B}, E_{\text {кон }}=1,4 \mathrm{~B}, \mathrm{pH}=7\right.$, деаэрирование растворов азотом) при различной скорости развертки потенциалов, мB/c: 1) 40; 2) 60; 3) 80; 4) 100; б) зависимость тока окисления $I_{p, 2}$ при $E_{p, 2} \approx 1,1$ В от корня квадратного из скорости развертки потенциала в интервале $v=40 \ldots 180 \mathrm{MB} / \mathrm{c}$ (фоновый электролит 0,05 $\mathrm{M} \mathrm{Na}_{2} \mathrm{SO}_{4}$ )

Fig. 5. a) voltammograms of the modified AuCCE electrode in a solution of $0,05 \mathrm{M} \mathrm{Na}_{2} \mathrm{SO}_{4}+1 \cdot 10^{-4} \mathrm{M} \mathrm{Na}_{2} \mathrm{~S}_{2} \mathrm{O}_{3}\left(E_{\text {init }}=0,0 \mathrm{~V}\right.$, $E_{\text {final }}=1,4 \mathrm{~V}, \mathrm{pH}=7$, solutions were deaerated with nitrogen) at different potential sweep rates, $\mathrm{mV} / \mathrm{s}:$ 1) 40 ; 2) 60; $3) 80$; 4$) 100 ; b$ ) dependence of anodic current $I_{p, 2}$ at $E_{p, 2} \approx 1,1 \mathrm{~V}$ on the square root of the potential sweep rate in the range of $v=40 \ldots 180 \mathrm{mV} / \mathrm{s}$ (supporting electrolyte $0,05 \mathrm{M} \mathrm{Na}_{2} \mathrm{SO}_{4}$ )
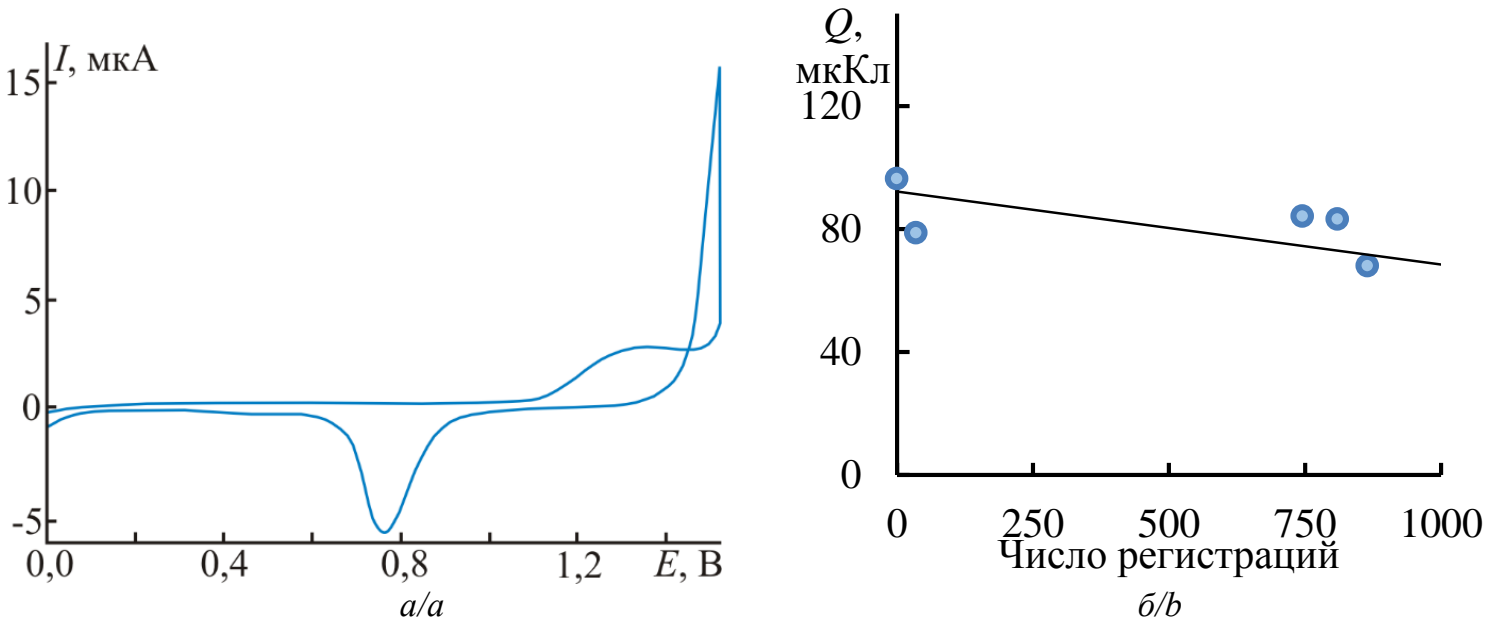

Pис. 6. а) ииклическая вольтамперограмма модифицированного электрода АиУКЭ в растворе 0,05 $\mathrm{M} \mathrm{H}_{2} \mathrm{SO}_{4}$ $\left(E_{\text {нач}}=0,0 \mathrm{~B}, E_{\text {кон }}=1,5 \mathrm{~B}, v=100 \mathrm{mB} / \mathrm{c}\right.$, деаэрирование раствора азотом); б) зависимость количества электричества $Q$, затраченного на катодное восстановлении (гидр)оксидов Аи в интервале потенциалов 1,0...0,6 B, от числа регистраций вольтамперограмм в растворе $0,05 \mathrm{M} \mathrm{Na}_{2} \mathrm{SO}_{4}+1 \cdot 10^{-4} \mathrm{M} \mathrm{Na}_{2} \mathrm{~S}_{2} \mathrm{O}_{3}$ без обновления поверхности электрода

Fig. 6. a) cyclic voltammogram of the modified AuCCE electrode in a solution of $0,05 \mathrm{M} \mathrm{H}_{2} \mathrm{SO}_{4}\left(E_{\text {init }}=0,0 \mathrm{~V}, E_{\text {final }}=1,5 \mathrm{~V}\right.$, $v=100 \mathrm{mV} / \mathrm{s}$, solutions were deaerated with nitrogen); $b$ ) dependence of the amount of electricity $Q$ consumed during cathodic reduction of $\mathrm{Au}$ (hydr)oxides in the potential range of 1,0...0,6 $\mathrm{V}$ on the number of the voltammogram recordings in a solution of $0,05 \mathrm{M} \mathrm{Na}_{2} \mathrm{SO}_{4}+1 \cdot 10^{-4} \mathrm{M} \mathrm{Na}_{2} \mathrm{~S}_{2} \mathrm{O}_{3}$ without renewing the electrode surface

Оценку правильности результатов определения концентрации $\mathrm{S}_{2} \mathrm{O}_{3}{ }^{2-}$-ионов по предлагаемому методу проводили с использованием метода добавок. Для этого первоначально регистрировали вольтамперо- грамму в 20 мл деаэрированного раствора фонового электролита (0,05 $\mathrm{M} \mathrm{Na}_{2} \mathrm{SO}_{4}$ или $\left.\mathrm{KNO}_{3}\right)$, затем вводили в ячейку при помощи микродозатора раствор $10^{-4} \mathrm{M}$ $\mathrm{Na}_{2} \mathrm{~S}_{2} \mathrm{O}_{3}$ и снова измеряли аналитический сигнал. 
Каждое измерение проводили три раза. Для вычисления предела обнаружения $c_{\min }$ использовали метод Кайзера, нижнюю границу определяемых концентраций $c_{\lim }$ находили из зависимости относительного стандартного отклонения $s_{\mathrm{r}}$ от содержания аналита при условии $s_{\mathrm{r}} \leq 0,33$ [32]. Результаты определения тиосульфата приведены в табл. 2 .

Таблица 2. Результаты определения тиосульфат-ионов в растворах методом «введено-найдено» $\left(V_{\text {нач }}\left(0,05 \quad M \quad K N O_{3}\right)=20 \quad\right.$ мл; $\quad E_{\text {нач }}=0,0 \quad B$; $E_{\text {кон }}=1,4 \mathrm{~B} ; v=100 \mathrm{MB} / \mathrm{c} ;$ деаэрирование растворов азотом); $n=3 ; P=0,95 ; t(P, f)=4,3$

Table 2. Results of the determination of $\mathrm{S}_{2} \mathrm{O}_{3}{ }^{2-}$ ions in solutions using the «introduced-found》 procedure $\left(V_{\text {init }}\left(0,05 \mathrm{MKNO}_{3}\right)=20 \mathrm{ml} ; E_{\text {init }}=0,0\right.$ $B ; E_{\text {final }}=1,4 \mathrm{~V} ; v=100 \mathrm{mV} / \mathrm{s}$; solutions were deaerated with nitrogen); $\quad n=3 ; \quad P=0,95$; $t(P, f)=4,3$

\begin{tabular}{|c|c|}
\hline $\begin{array}{c}\text { Введено } \mathrm{Na}_{2} \mathrm{~S}_{2} \mathrm{O}_{3}, c \cdot 10^{6} \mathrm{M} \\
\text { Introduced } \mathrm{Na}_{2} \mathrm{~S}_{2} \mathrm{O}_{3}, c \cdot 10^{6} \mathrm{M}\end{array}$ & $\begin{array}{c}\text { Найдено } \mathrm{Na}_{2} \mathrm{~S}_{2} \mathrm{O}_{3}, c \cdot 10^{6} \mathrm{M} \\
\text { Found } \mathrm{Na}_{2} \mathrm{~S}_{2} \mathrm{O}_{3}, c \cdot 10^{6} \mathrm{M}\end{array}$ \\
\hline 0,20 & $0,20 \pm 0,03$ \\
\hline 0,40 & $0,40 \pm 0,03$ \\
\hline 0,60 & $0,60 \pm 0,02$ \\
\hline 0,80 & $0,81 \pm 0,02$ \\
\hline 1,00 & $1,05 \pm 0,02$ \\
\hline
\end{tabular}

Примечание: предел обнаружения $c_{\min }=5 \cdot 10^{-8} \mathrm{M}(7,9$ мка/л), нижняя граница определяемых концентраций $c_{\text {lim }}=1,2 \cdot 10^{-7} \mathrm{M}$. Note: detection limit $c_{\min }=5 \cdot 10^{-8} \mathrm{M}\left(7,9 \mu \mathrm{g} \cdot \mathrm{l}^{-1}\right)$, the lower limit of the determined concentration $c_{\text {lim }}=1,2 \cdot 10^{-7} \mathrm{M}$.

Полученные результаты свидетельствуют о том, что качество измерений является удовлетворительным. Погрешность определения в области наиболее низких заданных концентраций $\mathrm{S}_{2} \mathrm{O}_{3}{ }^{2-}$-ионов не превышает $15 \%$ (табл. 2). Известно, что наиболее распространенными сопутствующими соединениями в тиосульфат-содержащих растворах являются сульфиды и сульфиты [4]. При разработке методики определения тиосульфата на основе результатов настоящей работы для устранения мешающего влияния этих соединений могут быть использованы осадители и/или маскирующие реагенты, применяемые при определении тиосульфата в аналитической практике (например, сульфит-ионы маскируют введением формальдегида в анализируемый раствор) [4].

\section{Выводы}

1. Анодное окисление тиосульфат-ионов на модифицированном частицами золота углеродсодер-

\section{СПИСОК ЛИТЕРАТУРЫ}

1. The impact and prospects of green chemistry for textile technology / Eds. Shahid-ul-Islam and B.S. Butola. - Kidlington: Woodhead Publishing, Elsevier, 2019. - 568 p.

2. Nashy E.-Sh. H.A., Eid K.A. High exhaustion of chrome tan, enhancement of leather properties and reduction of chrome tanning effluent impact // Egyptian Journal of Chemistry. - 2019. V. 62. - № 3. - P. 415-428

3. Basu O.D., De Souza N.P. Comparison of dechlorination rates and water quality impacts for sodium bisulfite, sodium thiosulfate and ascorbic acid // Journal of Water Supply: Research and Technology-Aqua. - 2011. - V. 60. - № 3. - P. 167-177. жащем композитном электроде АиУКЭ в фоновых электролитах $0,05 \mathrm{M} \mathrm{KNO}_{3}$ или $0,05 \mathrm{M} \mathrm{Na}_{2} \mathrm{SO}_{4}$ в условиях постояннотоковой вольтамперометрии с линейной разверткой потенциалов протекает в двух интервалах потенциалов $E=0,2 \ldots 0,6$ В и $0,8 \ldots 1,3$ В (х. с. э.) с максимумами анодного тока при $E_{\mathrm{p}, 1} \approx 0,35 \mathrm{~B}$ и $E_{\mathrm{p}, 2} \approx 1,1 \mathrm{~B}$. Величина анодного тока $I_{\mathrm{p}, 2}$ на порядок выше величины $I_{\mathrm{p}, 1}$, концентрационные зависимости величин $I_{\mathrm{p}, 1}$ и $I_{\mathrm{p}, 2}$ являются линейными в интервалах $c\left(\mathrm{~S}_{2} \mathrm{O}_{3}{ }^{2-}\right)=2 \cdot 10^{-}$ ${ }^{6} \ldots 8 \cdot 10^{-6} \mathrm{M}$ и $1 \cdot 10^{-7} \ldots 1 \cdot 10^{-5} \mathrm{M}$, соответственно. Показана целесообразность использования величины $I_{\mathrm{p}, 2}$ для определения низких концентраций $\mathrm{S}_{2} \mathrm{O}_{3}{ }^{2-}$-ионов.

2. Интерпретация процессов, протекающих в наблюдаемых интервалах потенциалов, проведена на основе расчетов диаграммы метастабильных ионно-молекулярных форм в системе $\mathrm{S}-\mathrm{Au}-\mathrm{H}_{2} \mathrm{O}$, a также литературных данных. Показано, что максимум анодного тока в области $E_{\mathrm{p}, 1}$ обусловлен протеканием совокупности электродных и химических реакций с участием промежуточных продуктов окисления тиосульфата (сульфит- и политионат-ионов, серы, комплексов Аu). Основным процессом в области $E_{\mathrm{p}, 2}$ является анодное окисление серы с наложением электрокаталитического процесса с участием (гидр)оксидов $\mathrm{Au}$.

3. Установлены условия вольтамперометрического определения тиосульфат-ионов на АиУКЭ: режим регистрации аналитического сигнала - вольтамперометрия постоянного тока с линейной разверткой потенциалов, скорость развертки $v=100 \mathrm{MB} / \mathrm{c}$; нейтральный фоновый электролит $0,05 \mathrm{M} \mathrm{KNO}_{3}$ или $0,05 \mathrm{M} \mathrm{Na}_{2} \mathrm{SO}_{4}$; область потенциалов регистрации аналитического сигнала: $E_{\text {нач }}=0,0 \mathrm{~B}$, $E_{\text {кон }}=1,4$ В (х. с. э.); природа аналитического сигнала: ток анодного окисления $I_{\mathrm{p}}$ в области потенциалов $0,8 \ldots 1,3 \mathrm{~B}, E_{\mathrm{p}, 2} \approx 1,1 \mathrm{~B}$; линейность концентрационной зависимости аналитического сигнала соблюдается в интервале концентраций $\mathrm{S}_{2} \mathrm{O}_{3}{ }^{2-}$ ионов $1 \cdot 10^{-7} \ldots 1 \cdot 10^{-5} \mathrm{M}$; предел обнаружения $c_{\min }=5 \cdot 10^{-8} \mathrm{M}(7,9$ мкг/л), нижняя граница определяемых концентраций $c_{\lim }=1,2 \cdot 10^{-7} \mathrm{M}$.

4. Полученные в работе результаты могут быть использованы при разработке (усовершенствовании) методик определения низких концентраций $\mathrm{S}_{2} \mathrm{O}_{3}{ }^{2-}$-ионов в технологических растворах, объектах окружающей среды, продуктах питания.

4. The importance of thiosalts speciation: review of analytical methods, kinetics, and treatment / J.C. Miranda-Trevino, M. Pappoe, K. Hawboldt, C. Bottaro // Critical Reviews in Environmental Science and Technology. - 2013. - V. 43. P. 2013-2070.

5. Leaching behavior of gold and silver from concentrated sulfide ore using ammonium thiosulfate / M. Bae, S. Kim, J. Sohn, D. Yang, H. Lee // Metals. - 2020. - V. 10. - P. 1029 (1-9).

6. Sodium thiosulfate improves intestinal and hepatic microcirculation without affecting mitochondrial function in experimental sepsis / J. Schulz, S. Kramer, Y. Kanatli, A. Kuebart, I. Bauer, O. Picker, C. Vollmer, R. Truse, A. Herminghaus // Frontiers in Immunology. - 2021. - V. 12. - P. 671935 (1-12). 
7. Hydrogen sulfide metabolite, sodium thiosulfate: clinical applications and underlying molecular mechanisms / M.Y. Zhang, G.J. Dugbartey, S. Juriasingani, A. Sener // International Journal of Molecular Sciences. - 2021. - V. 22. - P. 6452 (2-13).

8. Yates S.R., Ashworth D.J., Zhang Q. Effect of surface application of ammonium thiosulfate on field-scale emissions of 1,3dichloropropene // Science of the Total Environment. - 2017. V. 580. - P. 316-323.

9. Effects of thiosulfate as a sulfur source on plant growth, metabolites accumulation and gene expression in arabidopsis and rice / T. Nakajima, Y. Kawano, I. Ohtsu, A. MaruyuamaNakashita, A. Allahham, M. Sato, Y. Sawada, Y.M. Hirai, T. Yokoyama, N. Ohkama-Ohtsu // Plant Cell Physiology. 2019. - V. 60. - № 8. - P. 1683-1701.

10. СанПиН 2.3/2.4.3590-20. Санитарно-эпидемиологические требования к организации общественного питания населения. Ростов н/Д: Феникс, 2021. - 76 с

11. Hemmingsen $\mathrm{T}$. The electrochemical reaction of sulfur - oxygen compounds. P. I. A review of literature on the electrochemical properties of sulphur/sulphur - oxygen compounds // Electrochim. Acta. - 1992. - V. 37. - № 15. - P. 2775-2784.

12. Ciglenečki I., Ćosović B. Electrochemical determination of thiosulfate in seawater in the presence of elemental sulfur and sulfide // Electroanalysis. - 1997. - V. 9. - № 10. - P. 775-780.

13. Krista J., Kopanica M., Novotný L. Cathodic stripping voltammetry of thiosulphate at toxic concentrations // Analytica Chimica Acta. - 1999. - V. 386. - № 3. - P. 221-228.

14. Al electrode modified by $\mathrm{Au}$ atoms as a novel electrode for electrocatalytic oxidation of thiosulfate / R.E. Sabzi, A. Hassanzadeh, P. Heravi, K. Ghasemlu // Journal of the Chinese Chemical Society. - 2007. - V. 54. - P. 977-982.

15. Eftekhari A. Electrochemical behavior and electrocatalytic activity of a zinc hexacyanoferrate film directly modified electrode $/ /$ Journal of Electroanalytical Chemistry. - 2002. - V. 537. - P. 59-66

16. Pournaghi-Azar M.H., Razmi H. Electrocatalytic characteristics of thiosulfate oxidation at nickel plated aluminum electrode modified with nickel pentacyanonitrosylferrate films // Electroanalysis. 2001. - V. 13. - № 6. - P. 465-470.

17. Amperometric determination of thiosulfate at a surface-renewable nickel(II) hexacyanoferrate-modified carbon ceramic electrode / P. Wang, Y. Yuan, X. Jing, G. Zhu // Talanta. - 2001. - V. 53. P. 863-869.

18. Shankaran D.R., Narayanan S.S. Amperometric sensor for thiosulphate based on cobalt hexacyanoferrate modified electrode// Sensors and Actuators B: Chemical. - 2002. - V. 86. - № 2-3. P. $180-184$

19. Salimi A., Roushani M., Hallaj R. Micromolar determination of sulfur oxoanions and sulfide at a renewable sol-gel carbon ceramic electrode modified with nickel powder // Electrochimica Acta. - 2006. - V. 51. - № 10. - P. 1952-1959.

20. Ensafi A.A., Soleymani H.A., Mirmomtaz E. Determination of sulfur contents of $\mathrm{SO}_{3}{ }^{2-}, \mathrm{S}_{2} \mathrm{O}_{3}{ }^{2-}$ and $\mathrm{S}^{2-}$ based on the electrocatalytic interaction with homogeneous mediator tris $\left(2,2^{\prime}-\right.$ bipyridyl)Ru(II) // Microchemical Journal. - 2008. - V. 89. P. $108-115$.

21. Raoof J.B., Ojani R., Karimi-Maleh H. Electrocatalytic oxidation of thiosulfate at 2,7-bis(ferrocenylethyl)-fluoren-9-one-modified carbon paste electrode (2,7-BFEFMCPE): Application to the catalytic determination of thiosulfate in real sample // Chinese Chemical Letters. - 2010. - V. 21. - № 12. - P. 1462-1466.

22. Casella I.G., Contursi M., Desimoni E. Amperometric detection of sulfur-containing compounds in alkaline media // Analyst. - 2002. V. 127. - № 5. - P. 647-652.

23. Electrocatalytic oxidation and ion chromatography detection of $\mathrm{S}_{2} \mathrm{O}_{3}{ }^{2-}, \mathrm{SO}_{3}^{2-}$, I- and $\mathrm{SCN}-$ at glassy carbon electrode with functionalized multi-wall carbon nanotubes film / J.-M. Xu, Y.-P. Wang, Y.-Z. Xian, L. Jin // Chemical Research in Chinese Universities. - 2004. - V. 20. - № 5. - P. 529-533.

24. Amperometric determination of sodium thiosulfate using borondoped diamond electrodes applied to flow injection analysis / V. Suryanarayanan, Y. Zhang, S. Yoshihara, T. Shirakashi // Sensors and Actuators B: Chemical. - 2004. - V. 102. - № 1. P. $169-173$

25. A spectroelectrochemical study of surface species formed in the gold/thiosulfate system / R. Woods, G.A. Hope, K.M. Watling, M.I. Jeffrey // Journal of The Electrochemical Society. - 2006. V. 153. - № 7. - P. 105-113.

26. SERS and electrochemical studies of the gold-electrolyte interface under thiosulfate based leaching conditions / J.Y. Baron, J. Mirza, E. Nicol, S.R. Smith, J.J. Leitch, Y. Choi, J. Lipkowski // Electrochimica Acta. - 2013. - V. 111. - P. 390-399.

27. Green T.A., Roy S. Speciation analysis of Au(I) electroplating baths containing sulfite and thiosulfate // Journal of The Electrochemical Society. - 2006. - V. 153. - № 3. - P. C157-C163.

28. Electrolytic oxidation of sodium thiosulfate solution / F. Yokosuka, M. Takizawa, A. Okuwaki, T. Okabe // Chemistry Letters. 1974. - V. 3. - № 4. - P. 319-322.

29. Kovaleva S.V., Aksinenko O.S., Korshunov A.V. Electrooxidation of sulfite ions on a composite carbon-containing electrode modified with submicron gold particles // Journal of Analytical Chemistry. - 2020. - V. 75. - № 10. - P. 1348-1357.

30. Electro-oxidation of thiosulphate ion gold. Study by means of cyclic voltammetry and auger electron spectroscopy / A.M. Pedraza, I. Villegas, P.L. Freund, B. Chornik // Journal of Electroanalytical Chemistry. - 1988. - V. 250. - P. 443-449.

31. Burke L.D., Nugent P.F. The electrochemistry of gold. I. The redox behaviour of the metal in aqueous media // Gold Bulletin. 1997. - V. 30. - P. 43-53.

32. Doerffel K. Statistik in der analytischen chemie. - Leipzig: Deutscher Verlag für Grundstoffindustrie, 1990. - $256 \mathrm{~s}$.

Поступила 24.11.2021 2.

\section{Информация об авторах}

Аксиненко О.С., методист Управления образования Администрации Томского района.

Кориунов А.В., доктор химических наук, профессор кафедры строительного материаловедения Московского государственного строительного университета.

Ковалева С.B., доктор химических наук, профессор кафедры химии и методики обучения химии биологохимического факультета Томского государственного педагогического университета. 


\title{
VOLTAMMETRIC DETERMINATION OF THIOSULFATE IONS AT A CARBON-CONTAINING COMPOSITE ELECTRODE MODIFIED WITH GOLD PARTICLES
}

\author{
Olga S. Aksinenko ${ }^{1}$ \\ crumba88@mail.ru
}

\section{Andrey V. Korshunov2,} korshunovav@mgsu.ru

Svetlana V. Kovaleva ${ }^{3}$, svetkovaleva@rambler.ru

1 Department of Education, Tomsk District Administration, 2a, Kooperativny lane, Tomsk, 634009, Russia.

2 Moscow State University of Civil Engineering, 26, Yaroslavskoe highway, Moscow, 129337, Russia.

3 Tomsk State Pedagogical University, 60, Kievskaya street, Tomsk, 634061, Russia.

Relevance. Thiosulfates are widely used in industry (textile production, water treatment, metal extraction), agriculture (plant bloom control, soil fumigation, fertilizers), medicine (detoxification therapy), analytical chemistry. The areas of practical application of thiosulfates are determined by their high reducing and complexing activity, as well as by their oxidation products of practical significance (colloidal sulfur, polythionates). Despite the long experience of practical use of thiosulfates, the search for express, sensitive and accessible methods of their determination in technological media, environmental objects, and food is still ongoing. In this regard, the improvement of methods for the determination of thiosulfates is an urgent task.

Purpose: to determine the conditions for obtaining an analytical signal during the electrooxidation of thiosulfate ions using a carboncontaining composite electrode modified with gold particles.

Objects: sodium thiosulfate solutions.

Methods: DC voltammetry with linear potential sweep, cyclic voltammetry, scanning electron microscopy, energy-dispersive X-ray spectroscopy, modeling of redox equilibria.

Results. Electrooxidation of thiosulfate ions at a carbon-containing composite electrode modified with gold particles under conditions of direct current voltammetry with linear potential sweep (supporting electrolytes $0,05 \mathrm{M} \mathrm{KNO}_{3}$ or $0,05 \mathrm{M} \mathrm{Na}_{2} \mathrm{SO}_{4}$ ) proceeds at potentials of $0,2 \ldots 0,6$ and 0,8...1,3 V (vs. Ag/ $\mathrm{AgCl} / \mathrm{KCl}$ electrode) with anodic current maxima at $E_{p, 1} \approx 0,3$ and $E_{p, 2} \approx 1,1 \mathrm{~V}$. The value of the anode current of $I_{p, 2}$ is an order of magnitude higher than the value of $I_{p, 1}$, the concentration dependences of $I_{p, 1}$ and $I_{p, 2}$ are linear in the intervals $c$ $\left(\mathrm{S}_{2} \mathrm{O}_{3}{ }^{2-}\right)=1 \cdot 10^{-6} \ldots 1 \cdot 10^{-5}$ and $1 \cdot 10^{-7} \ldots 1 \cdot 10^{-5} \mathrm{M}$, respectively. The interpretation of electrode processes was carried out using calculated diagrams of metastable ion-molecular species in the $\mathrm{S}-\mathrm{Au}-\mathrm{H}_{2} \mathrm{O}$ system, as well as literature data. It was shown that anodic current in the $E_{p, 1}$ region is caused by a combination of electrode and chemical reactions involving intermediate products of thiosulfate oxidation (sulfite, polythionate ions, sulfur, $A u$ complexes). The main process at $E_{p, 2}$ is anodic oxidation of sulfur accompanied with electrocatalytic cycle involving $\mathrm{Au}$ (hydr)oxides. The use of the value of $I_{p, 2}$ at $E_{p, 2} \approx 1, .1 \mathrm{~V}$ to determine $\mathrm{S}_{2} \mathrm{O}_{3}{ }^{2-}$ ions of low concentrations was shown to be reasonable. The accuracy of the measurement results and the stability of the electrode function were evaluated during multiple registration of the analytical signal. The detection limit of $\mathrm{S}_{2} \mathrm{O}_{3}{ }^{2-}$ ions according to the proposed method is $\mathrm{C}_{\min }=5 \cdot 10^{-8} \mathrm{M}\left(7,9 \mu \mathrm{g} \cdot \mathrm{t}^{-1}\right)$, the lower limit of the determined concentration is $\mathrm{Clim}=1,2 \cdot 10^{-7} \mathrm{M}$. The results obtained in the work can be used in the development (improvement) of methods for determining low concentrations of $\mathrm{S}_{2} \mathrm{O}_{3}{ }^{2-}$ ions in technological solutions, environmental objects, food.

\section{Key words:}

Thiosulfate ions, gold particles, carbon-containing composite electrode, neutral electrolytes, DC voltammetry, anodic oxidation, metastable ion-molecular species of sulfur.

\section{REFERENCES}

1. The impact and prospects of green chemistry for textile technology. Eds. Shahid-ul-Islam, B.S. Butola. Kidlington, Woodhead Publ., Elsevier, 2019. $568 \mathrm{p}$.

2. Nashy E.-Sh. H.A., Eid K.A. High exhaustion of chrome tan, enhancement of leather properties and reduction of chrome tanning effluent impact. Egyptian Journal of Chemistry, 2019, vol. 62, no. 3 , pp. $415-428$.

3. Basu O.D., De Souza N.P. Comparison of dechlorination rates and water quality impacts for sodium bisulfite, sodium thiosulfate and ascorbic acid. Journal of Water Supply: Research and TechnologyAqua, 2011, vol. 60, no. 3, pp. 167-177.

4. Miranda-Trevino J.C., Pappoe M., Hawboldt K., Bottaro C. The importance of thiosalts speciation: review of analytical methods, kinetics, and treatment. Critical Reviews in Environmental Science and Technology, 2013, vol. 43, pp. 2013-2070.

5. Bae M., Kim S., Sohn J., Yang D., Lee H. Leaching behavior of gold and silver from concentrated sulfide ore using ammonium thiosulfate. Metals, 2020, vol. 10, pp. 1029 (1-9).

6. Schulz J., Kramer S., Kanatli Y., Kuebart A., Bauer I., Picker O., Vollmer C., Truse R., Herminghaus A. Sodium thiosulfate improves intestinal and hepatic microcirculation without affecting mitochondrial function in experimental sepsis. Frontiers in Iттиnology, 2021, vol. 12, pp. 671935 (1-12).

7. Zhang M.Y., Dugbartey G.J., Juriasingani S., Sener A. Hydrogen sulfide metabolite, sodium thiosulfate: clinical applications and underlying molecular mechanisms. International Journal of Molecular Sciences, 2021, vol. 22, pp. 6452 (2-13). 
8. Yates S.R., Ashworth D.J., Zhang Q. Effect of surface application of ammonium thiosulfate on field-scale emissions of 1,3 dichloropropene. Science of the Total Environment, 2017, vol. 580, pp. 316-323.

9. Nakajima T., Kawano Y., Ohtsu I., Maruyuama-Nakashita A., Allahham A., Sato M., Sawada Y., Hirai Y.M., Yokoyama T., Ohkama-Ohtsu N. Effects of thiosulfate as a sulfur source on plant growth, metabolites accumulation and gene expression in arabidopsis and rice. Plant Cell Physiology, 2019, vol. 60, no. 8, pp. $1683-1701$

10. SanPiN 2.3/2.4.3590-20. Sanitarno-epidemiologicheskie trebovaniya $k$ organizatsii obshchestvennogo pitaniya naseleniya [The Russ. Sanitary Rules and Regulations 2.3/2.4.3590-20. Sanitary and epidemiological requirements for the organization of public catering]. Rostov-on-Don, Phoenix, 2021.76 p.

11. Hemmingsen $\mathrm{T}$. The electrochemical reaction of sulfur - oxygen compounds. P. I. A review of literature on the electrochemical properties of sulphur/sulphur - oxygen compounds. Electrochim. Acta, 1992, vol. 37, no. 15, pp. 2775-2784.

12. Ciglenečki I., Ćosović B. Electrochemical determination of thiosulfate in seawater in the presence of elemental sulfur and sulfide. Electroanalysis, 1997, vol. 9, no. 10, pp. 775-780

13. Krista J., Kopanica M., Novotný L. Cathodic stripping voltammetry of thiosulphate at toxic concentrations. Analytica Chimica Acta, 1999, vol. 386, no. 3, pp. 221-228.

14. Sabzi R.E., Hassanzadeh A., Heravi P., Ghasemlu K. Al electrode modified by Au atoms as a novel electrode for electrocatalytic oxidation of thiosulfate. Journal of the Chinese Chemical Society, 2007, vol. 54, pp. 977-982.

15. Eftekhari A. Electrochemical behavior and electrocatalytic activity of a zinc hexacyanoferrate film directly modified electrode. Journal of Electroanalytical Chemistry, 2002, vol. 537, pp. 59-66.

16. Pournaghi-Azar M.H., Razmi H. Electrocatalytic characteristics of thiosulfate oxidation at nickel plated aluminum electrode modified with nickel pentacyanonitrosylferrate films. Electroanalysis, 2001, vol. 13, no. 6, pp. 465-470.

17. Wang P., Yuan Y., Jing X., Zhu G. Amperometric determination of thiosulfate at a surface-renewable nickel(II) hexacyanoferratemodified carbon ceramic electrode. Talanta, 2001, vol. 53, pp. 863-869.

18. Shankaran D.R., Narayanan S.S. Amperometric sensor for thiosulphate based on cobalt hexacyanoferrate modified electrode. Sensors and Actuators B: Chemical, 2002, vol. 86, no. 2-3, pp. 180-184.

19. Salimi A., Roushani M., Hallaj R. Micromolar determination of sulfur oxoanions and sulfide at a renewable sol-gel carbon ceramic electrode modified with nickel powder. Electrochimica Acta, 2006, vol. 51, no. 10, pp. 1952-1959.

20. Ensafi A.A., Soleymani H.A., Mirmomtaz E. Determination of sulfur contents of $\mathrm{SO}_{3}{ }^{2-}, \mathrm{S}_{2} \mathrm{O}_{3}{ }^{2-}$ and $\mathrm{S}^{2-}$ based on the electrocata- lytic interaction with homogeneous mediator tris(2,2'-bipyridyl) $\mathrm{Ru}(\mathrm{II})$. Microchemical Journal, 2008, vol. 89, pp. 108-115.

21. Raoof J.B., Ojani R., Karimi-Maleh H. Electrocatalytic oxidation of thiosulfate at 2,7-bis(ferrocenylethyl)-fluoren-9-one-modified carbon paste electrode (2,7-BFEFMCPE): Application to the catalytic determination of thiosulfate in real sample. Chinese Chemical Letters, 2010, vol. 21, no. 12, pp. 1462-1466.

22. Casella I.G., Contursi M., Desimoni E. Amperometric detection of sulfur-containing compounds in alkaline media, Analyst, 2002, vol. 127 , no. 5, pp. 647-652.

23. Xu J.-M., Wang Y.-P., Xian Y.-Z, Jin L. Electrocatalytic oxidation and ion chromatography detection of $\mathrm{S}_{2} \mathrm{O}_{3}{ }^{2-}, \mathrm{SO}_{3}{ }^{2-}, \mathrm{I}^{-}$and $\mathrm{SCN}^{-}$at glassy carbon electrode with functionalized multi-wall carbon nanotubes film. Chemical Research in Chinese Universities, 2004, vol. 20, no. 5, pp. 529-533.

24. Suryanarayanan V., Zhang Y., Yoshihara S., Shirakashi T. Amperometric determination of sodium thiosulfate using boron-doped diamond electrodes applied to flow injection analysis. Sensors and Actuators B: Chemical, 2004, vol. 102, no. 1, pp. 169-173.

25. Woods R., Hope G.A., Watling K.M., Jeffrey M.I. A spectroelectrochemical study of surface species formed in the gold/thiosulfate system. Journal of the Electrochemical Society, 2006, vol. 153, no. 7, pp. 105-113.

26. Baron J.Y., Mirza J., Nicol E., Smith S.R., Leitch J.J., Choi Y., Lipkowski J. SERS and electrochemical studies of the goldelectrolyte interface under thiosulfate based leaching conditions. Electrochimica Acta, 2013, vol. 111, pp. 390-399.

27. Green T.A., Roy S. Speciation analysis of $\mathrm{Au}(\mathrm{I})$ electroplating baths containing sulfite and thiosulfate. Journal of The Electrochemical Society, 2006, vol. 153, no. 3, pp. C157-C163.

28. Yokosuka F., Takizawa M., Okuwaki A., Okabe T. Electrolytic oxidation of sodium thiosulfate solution. Chemistry Letters, 1974, vol. 3, no. 4, pp. 319-322.

29. Kovaleva S.V., Aksinenko O.S., Korshunov A.V. Electrooxidation of sulfite ions on a composite carbon-containing electrode modified with submicron gold particles. Journal of Analytical Chemistry, 2020, vol. 75, no. 10, pp. 1348-1357.

30. Pedraza A.M., Villegas I., Freund P.L., Chornik B. Electrooxidation of thiosulphate ion on gold. Study by means of cyclic voltammetry and auger electron spectroscopy. Journal of Electroanalytical Chemistry, 1988, vol. 250, pp. 443-449.

31. Burke L.D., Nugent P.F. The electrochemistry of gold. I. The redox behaviour of the metal in aqueous media. Gold Bulletin, 1997, vol. 30 , pp. $43-53$

32. Doerffel K. Statistik in der analytischen chemie [Statistics in analytical chemistry]. Leipzig, Deutscher Verlag für Grundstoffindustrie, $1990.256 \mathrm{p}$

Received: 24 November 2021.

\section{Information about the authors}

Olga S. Aksinenko, methodologist, Department of Education, Tomsk District Administration.

Andrey V. Korshunov, Dr. Sc., professor, Moscow State University of Civil Engineering.

Svetlana V. Kovaleva, Dr. Sc., professor, Tomsk State Pedagogical University. 